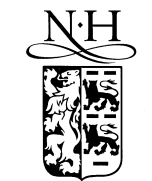

ELSEVIER

Research Policy 29 (2000) 257-272

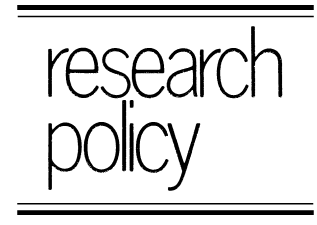

www.elsevier.nl/locate/econbase

\title{
A complexity approach to innovation networks. The case of the aircraft industry (1909-1997)
}

\author{
Koen Frenken *,1 \\ Department of Science and Technology Dynamics, University of Amsterdam, Nieuwe Achtergracht 166, 1018 WV, Amsterdam, Netherlands
}

\begin{abstract}
Successful innovation depends on complementary competencies in networks of producers, users, and governmental bodies. The effects of complementarities within innovation networks are modeled using Kauffman's $N K$-model. From the model, the hypothesis is derived that producers, users, and governments self-organize in specialized innovation networks: producers of particular technologies increasingly focus on particular user markets in particular countries. Data on 863 aircraft models (1909-1997) show these strong specialization patterns in the post-war period. Policy implications are indicated emphasizing the recent rise in transnational collaborations, which can be understood as a means of escaping historical specialization patterns. (C) 2000 Elsevier Science B.V. All rights reserved.
\end{abstract}

Keywords: Innovation network; Complexity; NK-model; Technological paradigm; Aircraft

\section{Introduction}

A nonlinear conception of product innovation takes into account the interdependency of different contributing actors. Networks have become understood as an important organizational form to coordinate the efforts of heterogeneous actors without restricting their individual goals. In this study, interdependencies among producers, users, and governments are modeled as complex innovation networks. We classify producers according to their technology, users according to market segments, and governments according to countries. Each threefold combination corresponds to one innovation network. The

\footnotetext{
*E-mail: k.frenken@geog.uu.nl

${ }^{1}$ Current Address: Centre for Science and Policy, University of Utreacht, P.O. Box, 80068, 3508TB, Utreacht, The Netherlands.
}

interdependencies within networks render the viability of each producer-user-government combination unpredictable since the functioning of a network cannot be aggregated from the qualities of the individual actors. Only when individual actors have complementary competencies, the network is expected to be viable.

The evolution of complex networks is analyzed using the $N K$-model (Kauffman, 1993). Since the $N K$-approach to complex systems is a general and content-free model, it serves us as a heuristic device to study the implications of the interdependencies in innovation networks. Our thesis is that only innovation networks that correspond to local optima are likely to survive. Local optima concern networks of producers, users and governments with complementary competencies. Actors can be expected to specialize in these local optima, which leads to an increasing differentiation of innovation networks 
into specific techno-economic arrangements at the national level.

The model is tested using data on 863 product innovations in the aircraft industry for the period 1909-1997. The case of aircraft is illuminating for three reasons. First, the aircraft history provides us with a long-term perspective. Second, the importance of collaboration between producers, users, and government has been recognized frequently in aircraft innovation (Mowery and Rosenberg, 1982; Hayward, 1983, 1986). Third, the history is well documented both qualitatively (Miller and Sawers, 1968; Constant, 1980) and quantitatively (Jane's, 1978, 1989, 1998). The results of the empirical analysis show the emergence of many technoeconomic specialization patterns across countries in the post-war period. This means that producers, users, and governments in aircraft technology are increasingly organized in specific innovation networks, which remain stable over time.

The model and the results have some interesting implications. Theoretically, "picking winners" is impossible a priori since complementarities within innovation networks are unpredictable. Therefore, a producer-user-government combination that "fits", well can only be found through experimentation. Empirically, we found that successful innovation networks in small countries are those that specialize in niche markets. In this way, they are able to limit price competition with networks in large countries that benefit from economies of scale. Furthermore, the recombination of national competencies within transnational networks provides countries with an enlarged space of possible innovations. Transnational collaborations like Airbus allow for the exploration of new combinations without necessarily affecting the national patterns of specialization. In the European context, this implies that the further integration of members' technology policies does not preclude the continuation or renewal of programs at the national level.

The paper is organized as follows. After a short review of evolutionary concepts related to innovation, a heuristic model of innovation networks is proposed in Section 3 using Kauffman's $N K$-model of complex systems. In Section 4, we develop an empirical methodology, which is then used in Section 5 to analyze data on aircraft innovations. In
Section 6, we discuss the implications of the model and the results for the understanding of transnational networks, and we list the conclusions in Section 7.

\section{Evolutionary concepts of innovation}

Traditional evolutionary models of technological change hold that market selection operates upon a variation of technologies. Firms introducing a technology may be uncertain about its profitability, but the market solves the information problem by selecting the ones with higher profitability. Less efficient production techniques are substituted for more efficient production techniques through a process of competition and imitation among firms (Alchian, 1950).

More recently, studies on the role of the market environment have abandoned the concept of a given "natural" environment selecting upon a variation of technologies. Instead, selection is understood to take place on the basis of user expectations and practices, which are, in turn, subject to change. As technologies are implemented in user contexts, new properties are recognized by users, which shape their future development (Rosenberg, 1982; Von Hippel, 1988). The extent to which user contexts affect the product strategies of producers depends on the quality of the interaction between users and producers (Lundvall, 1988).

The importance of mutual feedback among producers and users also underlies the concept of trajectories as a recursive process shaping technological development. Though the trajectory concept started out mainly by referring to the technical aspects of innovation, market feedback has always been recognized (Nelson and Winter, 1977; Dosi, 1982). In evolutionary extensions of this approach, a trajectory has come to be understood as a particular stable fit between technological properties and the market environment. Differentiation strategies aiming to limit price competition lead to the bifurcation of a trajectory into two or more trajectories. Along these trajectories, R\&D concentrates on specific trade-offs to improve products in specific market segments. The resulting specialization patterns of particular tech- 
nologies in different submarkets resemble the evolutionary branching of species into different selection environments (Saviotti, 1996; Windrum and Birchenhall, 1998; Frenken et al., 1999b). ${ }^{2}$

The nature of the interaction between producers and users also depends on mediating institutions that favor the development of particular technologies and markets (Freeman and Perez, 1988; Lundvall, 1988). Institutions "co-evolve" with technologies and market environments as Nelson (1994) puts it. For example, the refinement of patent law in the 1870 s has been crucial in the development of the German chemical industry (Van den Belt and Rip, 1987). From an evolutionary perspective, the institutional framework can be considered as both a locus of variation and a locus of selection. Institutions and policies enable the creation of new technologies while they constrain the range of technologies by selecting upon them. Technology policies can thus be aimed at supporting or discouraging the adoption of a particular technology by producers at the supply side and users at the demand side. Since, as argued above, user and producer strategies are partly interdependent, effective policies are likely to be mixed ones aiming at changing both supply and demand conditions.

The mutual relationships between technological, market, and institutional developments call for a three-dimensional evolutionary model (cf. Leydesdorff, 1998). The "triple helix" framework attempts to model all three loci of variation and selection as interrelated processes which transform existing relations between the techno-scientific, economic, and political spheres (Leydesdorff and Etzkowitz, 1996). While the triple helix model concentrates on university-industry-government relations, it can be taken as a general model of innovation networks contain-

\footnotetext{
${ }^{2}$ Arthur (1989) showed that the presence of network externalities among adopting agents may lead to technological standardization thus leading to the disappearance of branches. However, recent simulation models of local externalities show that competing technologies may survive in differentiated markets instead of lock-in into one technology in Arthur's case of global externalities (Dalle, 1997).
}

ing (at least) a knowledge generator, a user environment and a regulatory body. In the following study, these actors concern producers, users and national governments, respectively. These actors are involved in innovation networks and cooperate in various ways at different stages of the innovation process. For an innovation to become successful, their competencies need to be complementary in order to supplement their knowledge bases.

This approach differs from most institutional approaches which concentrate on the effects of (national) institutions on technological and market developments without analyzing how institutions are shaped by existing technoeconomic arrangements. The prevailing distribution of technologies and markets, however, affects in turn institutional developments. A country specializing in military technology (e.g., France) can be expected to develop institutions different from those in a country specializing in, for example, distribution and related services (e.g., The Netherlands). Nonlinear innovation models help in the understanding of all relations from a network perspective.

\section{A complexity approach to innovation networks}

Complex systems theory provides us with heuristic models to study the effects of interdependencies within networks. One of the models that has been developed recently is the $N K$-model (Kauffman, 1993), which can be used to analyze complementarities between actors in innovation networks. ${ }^{3}$ In the $N K$-model, $N$ stands for the number of elements, so we have $N=3$ in our case of producer-usergovernment networks. We classify producers according to their technology, users according to their

\footnotetext{
${ }^{3}$ The $N K$-model was originally developed by Kauffman to study the evolutionary dynamics of biological populations, and it has been used to study the evolution of organizational structures of firms (Levinthal, 1997), and to analyze problem-solving strategies in complex optimization problems (Frenken et al., 1999a). For reflections on possible applications of the $N K$-model in the field of scientometrics, see Scharnhorst (1998), and for related models applied to social phenomena, see Axelrod (1997).
} 


$\begin{array}{lcccc} & \mathrm{f}_{\mathrm{x} .} & \mathrm{f}_{. y .} & \mathrm{f}_{. z} & \mathrm{f}_{\mathrm{xyz}} \\ \text { 000: } & 0.2 & 0.6 & 0.8 & 0.53 \\ 001: & 0.2 & 0.6 & 0.5 & 0.43 \\ 010: & 0.2 & 0.9 & 0.8 & 0.63 \\ 011: & 0.2 & 0.9 & 0.5 & 0.53 \\ 100: & 0.7 & 0.6 & 0.8 & 0.70 \\ 101: & 0.7 & 0.6 & 0.5 & 0.60 \\ 110: & 0.7 & 0.9 & 0.8 & 0.80 \\ 111: & 0.7 & 0.9 & 0.5 & 0.70\end{array}$

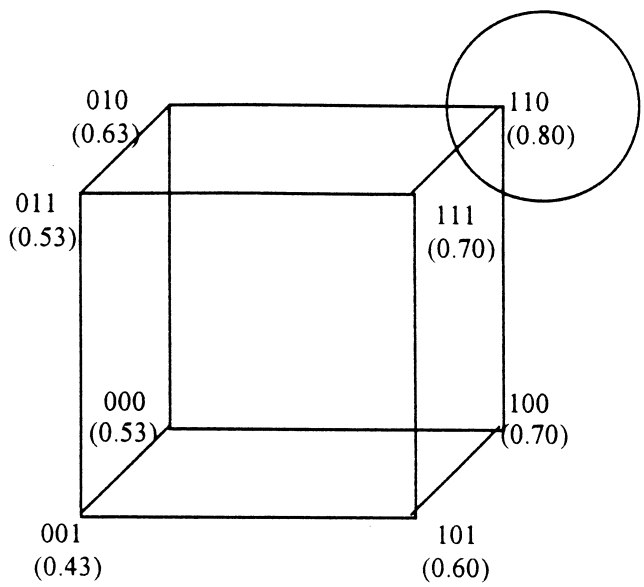

Fig. 1. Fitness landscape for innovation networks without interdependencies $(N=3, K=0)$.

market segments, and governments by their countries. $^{4}$ Each combination among a technology, a market, and a country then represents an innovation network of a producer type, a user type, and a government type. Innovation networks thus evolve within this three-dimensional space of possibilities. Selection, then, operates on the relative success of the various producer-user-government combinations in producing innovations. The success of an innovation network is taken to be the number of product innovations it develops.

In the simplest case, innovation networks can be formed by means of a combination between one out of two producer types $(X=\{0,1\})$, one out of two user types $(Y=\{0,1\})$ and one out of two governments $(Z=\{0,1\})$. Thus, $X=0$ stands for technology " 0 " and $X=1$ for technology " 1 "', $Y=0$ for market " 0 " and $Y=1$ for market " 1 ", and $Z=0$ for country " 0 ", and $Z=1$ for country " 1 ". In total, the possibility space contains $2^{3}=8$ networks $X Y Z$, namely, 000, 001, 010, 011, 100, 101, 110, and 111.

In the $N K$-model, the quality or fitness of an actor in the network is simulated using random

\footnotetext{
${ }^{4}$ Thus, we assume that government policies can be distinguished on national levels. Alternatively, one may aggregate national governments into groups of countries with similar policies, or decompose national governments in local governments with different policies, if sufficient information on this can be found.
}

values for the fitness of each actor, and the aggregated fitness of the network is calculated as the average $f_{X Y Z}$ of the fitness values of all actors. The complexity of a network is indicated by $K$ that refers to the number of dependency relations within a network and has a minimum possible value of $K=0$ and a maximum possible value of $K=N-1$. Thus, if the functioning of an actor is not affected by other actors in the network we have $K=0$, while if the functioning of an actor is affected by all other actors in the network, we have $K=2$.

$K=0$ : In the case that the functioning of an actor is not affected by others, the fitness value for an actor is drawn only once for state " 0 ", and for state " 1 ". Fig. 1 lists a simulation of fitness values for different technology-market-country combinations for $K=0$. In the first three columns the fitness values of each actor type $f_{X}, f_{. Y}$, and $f_{. Z}$ are given, and the fourth column the fitness of the network as a whole $f_{X Y Z}$, which equals the average of the fitness values of actors. The distribution of fitness values over the possible combinations is called a "fitness landscape'.

The absence of any interdependency among actors in the case of $K=0$ implies that the fitness value of one actor type is always the same for each combination of the other two actors. For example, the fitness value of producer type $X=0$ is $f_{0 .}=0.2$ for all combinations of user type $Y$ and government type $Z$ (000, 001, 010, and 011). And, for producer type $X=1$ the value is $f_{1 .}=0.7$ for all combinations of 
user type $Y$ and government type $Z(100,101,110$, and 111). This reflects that in the case of $K=0$, actors function independently from each other. For this reason, the optimum with the highest fitness value $f_{X Y Z}$ is simply the network in which all actors have the highest fitness value. In this simulation, the optimum is combination 110 , which would correspond in the example with the network that combines technology " 1 " with market " 1 " in country " 0 ". This implies that for any network except for the optimum network, the fitness can always be improved by substituting one actor. By means of this trial-and-error substitution procedure, the fitness landscape can be "climbed" until the optimum is found. Put another way, as long as the optimum is not found, there are always two actors that share an "interest" in substituting the third actor as to move to a better innovation network.

$K=2$ : In the case that the functioning of an actor type is affected by the other types of actors present in a network $(K=2)$, we have a network of maximum complexity. In a network of maximum complexity the competencies of actors are all interdependent. Following Kauffman (1993), to analyze the functioning of such complex networks, the fitness value of each actor must be drawn for each possible combination separately, since the fitness of an actor depends on the two other members in the network. A simulation is given in Fig. 2. Now, the fitness of particular actor types is different for different combinations of the two other actor types. For example, for producer type $X=0, f_{0}=0.6$ when $Y=0$ and $Z=$ $0, f_{0 .}=0.1$ when $Y=0$ and $Z=1, f_{0 .}=0.7$ when $Y=1$ and $Z=0$, and $f_{0 .}=0.3$ when $Y=1$ and $Z=1$. The interdependencies among actors lead actors to function well in some networks, while poorly in other networks. As a consequence of these interdependencies, the possibility space contains several optima, i.e., several combinations with a fitness value that cannot be improved by substituting one actor in the network. In this simulation, we have combinations 100 and 010 as optima. Network 100 is the global optimum since it has the highest fitness value, while 010 is a local optimum. By trial-and-error substitution of actors, actors move over the fitness landscape until one of the optima is found. Importantly, this search procedure will not necessarily lead to the global optimum, but possibly lead the sub-optimal local optimum.

Optima are different from each other with respect to at least two actors, and in our case of $N=3$, at most three actors. This means that two or all three actors share an interest to stick to a local optimum, since they cannot improve the network by substituting one actor. Thus, once a local optimum is found, the majority of actors share a common interest to stick to it, which renders the formation of networks corresponding to local optima to some degree irreversible ("lock-in") The existence of local optima leads us to the hypothesis that networks will increasingly differentiate into the combinations between producers, users and governments that correspond to

$\begin{array}{lcccc} & \mathrm{f}_{\mathrm{x} .} & \mathrm{f}_{. \mathrm{y} .} & \mathrm{f}_{. z} & \mathrm{f}_{\mathrm{xyz}} \\ \text { 000: } & 0.6 & 0.3 & 0.5 & 0.47 \\ \text { 001: } & 0.1 & 0.5 & 0.9 & 0.50 \\ \text { 010: } & 0.7 & 0.9 & 0.5 & 0.70 \\ \text { 011: } & 0.3 & 0.5 & 0.8 & 0.53 \\ \text { 100: } & 0.9 & 0.9 & 0.7 & 0.83 \\ \text { 101: } & 0.7 & 0.2 & 0.3 & 0.40 \\ \text { 110: } & 0.6 & 0.7 & 0.6 & 0.63 \\ 111: & 0.4 & 0.8 & 0.1 & 0.43\end{array}$

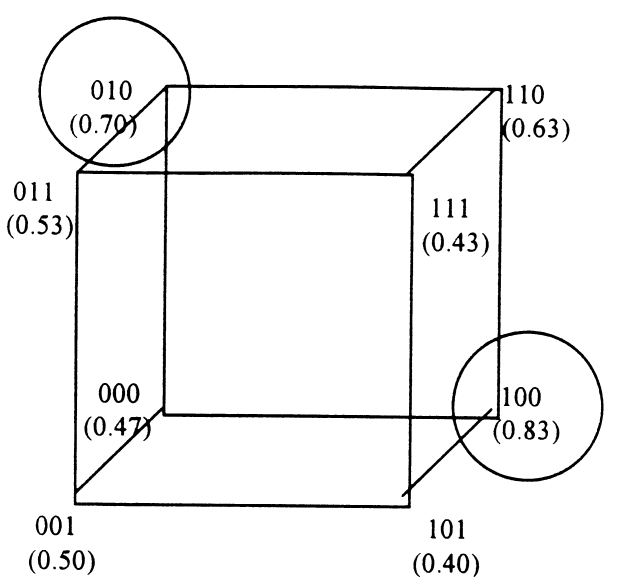

Fig. 2. Fitness landscape for innovation networks with interdependencies $(N=3, K=2)$. 
these local optima. As producers are classified according to their technology, users according to their market segment, and government according to countries, we expect innovations in a specific technology to become coupled to a particular market in a particular country.

In sum, the constitution of an innovation network can be thought of as a combinatorial problem. By experimenting with different combinations, actors "learn' the viability of different networks. Once they find a local optimum, they are expected to exploit this combination further along a "technological trajectory'. For this reason, one expects an increasing specialization among networks that couple a specific technology to a specific market and specific national institutions. The model does not intend to describe interactions among actors in innovation networks in any detailed way, nor does it attempt to predict the emergence of specific networks. It serves as a heuristic device to understand the relation between the complexity of networks and the patterns of specialization among them. On the basis of this hypothesis, we expect the degree of specialization among networks to increase over time, as the ones corresponding to local optima are most successful.

\section{Methods and materials}

Below, specialization patterns among technologies, markets and countries are analyzed using data on 863 aircraft innovations introduced during the period 1909-1997. The data have been collected from Jane's (1978; 1989; 1998). Each innovation is classified in a technology category $i$ along the $X$-axis, a market category $j$ along the $Y$-axis, and a country category $k$ along the $Z$-axis. The classes that are distinguished along each dimension are listed in Table 1 . The technology categories along the $X$-axis represent the different producer groups, and are distinguished on the basis of the engine type (piston propeller, turbopropeller, turbojet, turbofan, turboshaft, propfan, rocket) and the lift configuration used in the aircraft (monoplane, biplane, triplane, tiltrotor). Market categories are based on the primary application of the aircraft and represent the user groups. Categories along the $Z$-axis refer to the country of development, thus representing nation states. ${ }^{5}$ As an example, the Boeing 747 is classified as a product innovation in the network of "turbofan" producers, "passenger aircraft" users, and the "USA" government.

In this view, a single firm may be present in several networks at the same time, as it is the case with multi-product and multinational companies. For example, in the 1920s, Fokker developed piston propeller biplanes in the Netherlands for the bomber market, and piston propeller monoplanes in the United States for the passenger market. The unit of analysis here is not the firm, but the innovation network as classified by a technology-market-country combination as we hypothesized that complementarities are localized within networks of producers, users and governments.

Since we distinguish up to nine technologies, eight markets and 31 countries, the number of possible networks is very large, and consequently, a large number of these networks can be expected to correspond to local optima. The existence of many local optima makes it even more difficult for Actors to find the global optimum, and can therefore be expected to exploit a local optimum once they find one, rather than spending time and resources in experimenting in other networks. These local optima are expected to unfold gradually in the course of the industry's evolution, as networks that do not correspond to optima tend to disappear. Only relatively successful technology-market-country combinations corresponding to local optima will continue to develop new products. This leads to an increasing degree of specialization among innovation networks over time.

A straightforward way to measure the degree of specialization among different technology-marketcountry triples is to calculate the mutual information among the three frequency distributions of technologies, markets and countries. This is a measure of dependence between distributions, and originated from information theory as a measure of transmission, defined as $T$ (Theil, 1967, 1972; Leydesdorff,

\footnotetext{
${ }^{5}$ In the case of transnational collaborations among firms, the innovation is attributed to all participating countries weighted by their financial share. We elaborate on the issue of transnational networks in Section 6.
} 
Table 1

Classes

$X$ : Technologies $i$

piston propeller monoplane, piston propeller biplane, piston propeller triplane, turbopropeller monoplane, turbojet monoplane, turbofan monoplane, rocket monoplane, propfan monoplane, turboshaft tiltrotor

$Y$ : Markets $j$

$Z$ : Countries $k$ passenger aircraft, business aircraft, cargo aircraft, fighters, bombers, trainers, STOL-aircraft, VTOL-aircraft ${ }^{\mathrm{a}}$ Argentina, Australia, Austria, Belgium, Brazil, Canada, China, Czechoslovakia, France, Germany, Great Britain, Hungary, Italy, India, Indonesia, Israel, Japan, The Netherlands, New Zealand,

Poland, Romania, South Africa, South Korea, Spain, Sweden, Switzerland, Taiwan,

Ukraine, USA, USSR/Russian Federation, Yugoslavia

${ }^{\mathrm{a}}$ STOL and VTOL stand for Short and Vertical Take-Off and Landing, respectively.

1995). The three-dimensional mutual information is given by: ${ }^{6}$

$$
\begin{aligned}
& T(X, Y, Z) \\
& \quad=\sum_{i=1}^{I} \sum_{j=1}^{J} \sum_{k=1}^{K} p_{i j k} \log _{2}\left(p_{i j k} /\left(p_{i .} \cdot p_{. j .} \cdot p_{. k}\right)\right) \\
& (i=1, \ldots, I ; j=1, \ldots, J ; k=1, \ldots, K)
\end{aligned}
$$

where $p_{i j k}$ stands for the relative frequency of product innovations using technology $i$ developed for market $j$ in country $k$. Absence of specialization would imply that $p_{i j k}$ equals $\left(p_{i .} p_{. j .} p_{. k}\right)$ for all $p_{i j k}$, which results in a $T$-value equal to zero. In all other cases, $T(X, Y, Z)$ takes on a positive value, and the higher the $T$-value the higher the degree of specialization among innovation networks.

The three-dimensional specialization measure $T(X, Y, Z)$, however, is only a summary indicator. As noted above, specialization patterns among innovation networks are possible in two dimensions since local optima differ in at least two dimensions. In a third dimension, local optima may be the same. For example, in the simulation in Fig. 2, the local optima are " 010 " and " 100 " and thus have the same country-value “ 0 ', Mutatis mutandis, local optima may contain the same technology or the same market. To detect in which pairs of dimensions the specialization patterns are most pronounced, we thus have to look for relatively frequent technologymarket, technology-country and market-country couples (and not only for relatively frequent technology-market-country triples). To this end, we calculate for each period the two-dimensional matrices of

\footnotetext{
${ }^{6}$ For $x=0, x \log _{2} x \equiv 0$
}

the relative frequencies of combinations between technologies and markets $\left(p_{i j}\right)$, between technologies and countries $\left(p_{i . k}\right)$, and between markets and countries $\left(p_{. j k}\right)$. We compute for each of these frequency-matrices the mutual information, which measures the degree of dependence between two dimensions. The formulas for the two-dimensional mutual information values are given by:

$$
\begin{aligned}
& T(X, Y)=\sum_{i=1}^{I} \sum_{j=1}^{J} p_{i j .} \log _{2}\left(p_{i j .} /\left(p_{i .} \cdot p_{. j .}\right)\right) \\
& (i=1, \ldots, I ; j=1, \ldots, J) \\
& T(X, Z)=\sum_{i=1}^{I} \sum_{k=1}^{K} p_{i . k} \log _{2}\left(p_{i . k} /\left(p_{i .} \cdot p_{. k}\right)\right)^{7} \\
& (i=1, \ldots, I ; k=1, \ldots, K) \\
& T(Y, Z)=\sum_{j=1}^{J} \sum_{k=1}^{K} p_{. j k} \log _{2}\left(p_{. j k} /\left(p_{. j .} \cdot p_{. k}\right)\right) \\
& (j=1, \ldots, J ; k=1, \ldots, K)
\end{aligned}
$$

\subsection{Example}

Consider now a fictitious example of a possibility space among two technologies $(X=\{0,1\})$, two markets $(Y=\{0,1\})$ and two countries $(Z=\{0,1\})$, and assume that there are two optima, which are 000 and 111. These two combinations are expected to be

\footnotetext{
${ }^{7}$ Note the relation between mutual information $T(X, Z)$ for technologies and countries and the Soete-Wyatt RTA-index which stands for "Revealed Technological Advantage"' (Soete and Wyatt, 1983). Mutual information equals the weighted sum of the log of the RTA.
} 
relatively frequent, while other combinations relatively less frequent. Consider then the following fictive frequencies for 10 product innovations: three times 000 , one times 010 , one times 101 , and five times 111. The three-dimensional frequencies of this population of products are:

$$
\begin{array}{ll}
p_{000}=0.3 & p_{010}=0.1 \\
p_{001}=0.0 & p_{011}=0.0 \\
p_{100}=0.0 & p_{110}=0.0 \\
p_{101}=0.1 & p_{111}=0.5
\end{array}
$$

The high frequencies of the local optima 000 and 111 show that there exists a specialization pattern among a network developing products with technology 0 for market 0 in country 0 jet and a network developing technology 1 for market 1 in country 1 .

To calculate the $T(X, Y, Z)$-value, we first need to calculate the one-dimensional frequencies which are the sum of three-dimensional frequencies over one dimension. We get:

$$
\begin{aligned}
& p_{0 .}=p_{000}+p_{010}+p_{001}+p_{011}=0.4 \\
& p_{1 .}=p_{100}+p_{110}+p_{101}+p_{111}=0.6 \\
& p_{.0 .}=p_{000}+p_{100}+p_{001}+p_{101}=0.4 \\
& p_{.1}=p_{010}+p_{110}+p_{011}+p_{111}=0.6 \\
& p_{.0}=p_{000}+p_{100}+p_{010}+p_{110}=0.4 \\
& p_{.1}=p_{001}+p_{101}+p_{011}+p_{111}=0.6
\end{aligned}
$$

Using formula (1), the value for $T(X, Y, Z)$ then becomes:

$$
\begin{aligned}
T(X, Y, Z)= & 0.3 \log _{2}(0.3 / 0.064) \\
& +0.1 \log _{2}(0.1 / 0.096) \\
& +0.1 \log _{2}(0.1 / 0.144) \\
& +0.5 \log _{2}(0.5 / 0.216) \\
= & 1.23 \mathrm{bits}
\end{aligned}
$$

The three-dimensional mutual information value $T(X, Y, Z)$ indicates the overall degree of specialization among networks. This is clearly positive in the fictitious example, since we have a clear specialization pattern among network 000 and network 111 .

The three-dimensional specialization pattern can then be further analyzed by looking at the mutual information values of $T(X, Y), T(X, Z)$ and $T(Y, Z)$ for the two-dimensional frequency distributions. For the two-dimensional frequencies, we get:

$$
\begin{aligned}
& p_{00 .}=p_{000}+p_{001}=0.3 \\
& p_{10 .}=p_{100}+p_{101}=0.1 \\
& p_{01 .}=p_{010}+p_{011}=0.1 \\
& p_{11 .}=p_{110}+p_{111}=0.5 \\
& p_{0.0}=p_{000}+p_{010}=0.4 \\
& p_{1.0}=p_{100}+p_{110}=0.0 \\
& p_{0.1}=p_{001}+p_{011}=0.0 \\
& p_{1.1}=p_{101}+p_{111}=0.6 \\
& p_{.00}=p_{000}+p_{100}=0.3 \\
& p_{.10}=p_{010}+p_{110}=0.1 \\
& p_{.01}=p_{001}+p_{101}=0.1 \\
& p_{.11}=p_{011}+p_{111}=0.5
\end{aligned}
$$

Using formulas (2)-(4), the two-dimensional mutual information values become:

$$
\begin{aligned}
& T(X, Y)=0.3 \log _{2}(0.3 / 0.16) \\
& +0.1 \log _{2}(0.1 / 0.24) \\
& +0.1 \log _{2}(0.1 / 0.24) \\
& +0.5 \log _{2}(0.5 / 0.36) \\
& =0.26 \mathrm{bits} \\
& T(X, Z)=0.4 \log _{2}(0.4 / 0.16) \\
& +0.6 \log _{2}(0.6 / 0.36) \\
& =0.97 \mathrm{bits} \\
& T(Y, Z)=0.3 \log _{2}(0.3 / 0.16) \\
& +0.1 \log _{2}(0.1 / 0.24) \\
& +0.1 \log _{2}(0.1 / 0.24) \\
& +0.5 \log _{2}(0.5 / 0.36) \\
& =0.26 \text { bits }
\end{aligned}
$$

The results show that, in this fictitious example, the specialization between technologies and countries as indicated by $T(X, Z)$ is strongest $(0.97$ bits $)$. Producers of technology " 0 " are all located in country " 0 " and producers of technology " 1 ", are all located in country " 1 ". The specialization between 
technologies and markets $T(X, Y)$, and between markets and countries $T(Y, Z)$ is less pronounced $(0.26$ bits), since the two technologies are used in both markets, and the two markets are covered by both countries but to different extents. Concluding, in this fictitious example, the strongest complementarities are between technologies and countries, and weaker complementarities are found between technologies and markets, and between markets and countries.

\section{Results}

We calculated the three- and two-dimensional mutual information values for the distributions of aircraft innovations for moving 10-year periods during the whole period between 1909 and 1997 (so we have period 1: 1909-1918, period 2: 1910-1919, etc.). ${ }^{8}$ Thus, the frequency distributions are based on the set of new aircraft models that have been introduced during a 10-year period. The years in the schemes refer to the last year of each period (so 1918 refers to the period 1909-1918, etc.).

\subsection{Three-dimensional specialization pattern}

In Scheme 1, the results for the three-dimensional mutual information $T(X, Y, Z)$ are exhibited. The trend is pronounced: low values till 1945 with lowest values during the Second World War, rising values between 1945 and 1965, and high values hereafter. These results show that before 1945, countries did not specialize in specific technologies and markets, while in the post-war period, specialization patterns occurred rapidly. Following the $N K$-model, this result suggests the interdependencies between producers, users and government have become stronger over time as the mutual information among them is rising. The increasing degree of specialization among innovation networks as a result of networking is thus to be understood as a historical phenomenon, which started in the aircraft industry after the Second World War.

\footnotetext{
${ }^{8}$ Calculations for 5-year and 15-year periods yielded similar results as the ones reported here.
}

The low values before 1945 indicate that little specialization among innovation networks had emerged during this period. The values increase to some extent in the late 1920s, but decrease again during the 1930s and approach their lowest values in the early 1940s. At this point in time, aircraft technology was standardized in piston propeller monoplane design that established itself as the technological paradigm in the majority of markets and countries. In particular, the Douglas DC3 introduced in 1936 became the dominant design concept during this period (Miller and Sawers, 1968). This is reflected in the decreasing values during the period 1930-1945.

After 1945, the mutual information values are rapidly rising. A number of new technologies have been introduced just after the Second World War, which were coupled to specific market segments: turboprops predominantly to bomber and cargo aircraft, jets predominantly to fighter aircraft, and turbofans predominantly to passenger aircraft. ${ }^{9}$ The older piston propeller technology could survive in the niche of business and trainer aircraft. Each technology thus specialized in the niche in which it has a comparative advantage over the other technologies, thus giving rise to a branching out of technologies in different niches (Frenken et al., 1999b).

The rising values for $T(X, Y, Z)$ further reflect that specific countries came to dominate the development of specific technologies in specific market segments. Countries became increasingly "committed" to a particular technological trajectory. From formula (1) for the mutual information we can derive for each network the extent to which it is specialized. This is indicated by the value for $p_{i j k} \log _{2}$ $\left(p_{i j k} / p_{i .} p_{. j .} p_{. k}\right)$ for all ijk triples, since $T(X, Y, Z)$ equals the sum of all $p_{i j k} \log _{2}\left(p_{i j k} / p_{i .} p_{. j .} p_{. k}\right)$-values. Thus, the specialization value $p_{i j k} \quad \log _{2}$ $\left(p_{i j k} / p_{i .} p_{. j .} p_{. k}\right)$ of each individual producer-usergovernment combination ijk gives us a ranking of networks from most specialized to least specialized.

\footnotetext{
${ }^{9}$ This finding that new technologies are first introduced in specific market segments before possibly diffusing in other segments can be explained as a strategy to limit competition from established technologies. The finding fits the notion of strategic niche-management (Kemp, 1994; Rip et al., 1995).
} 


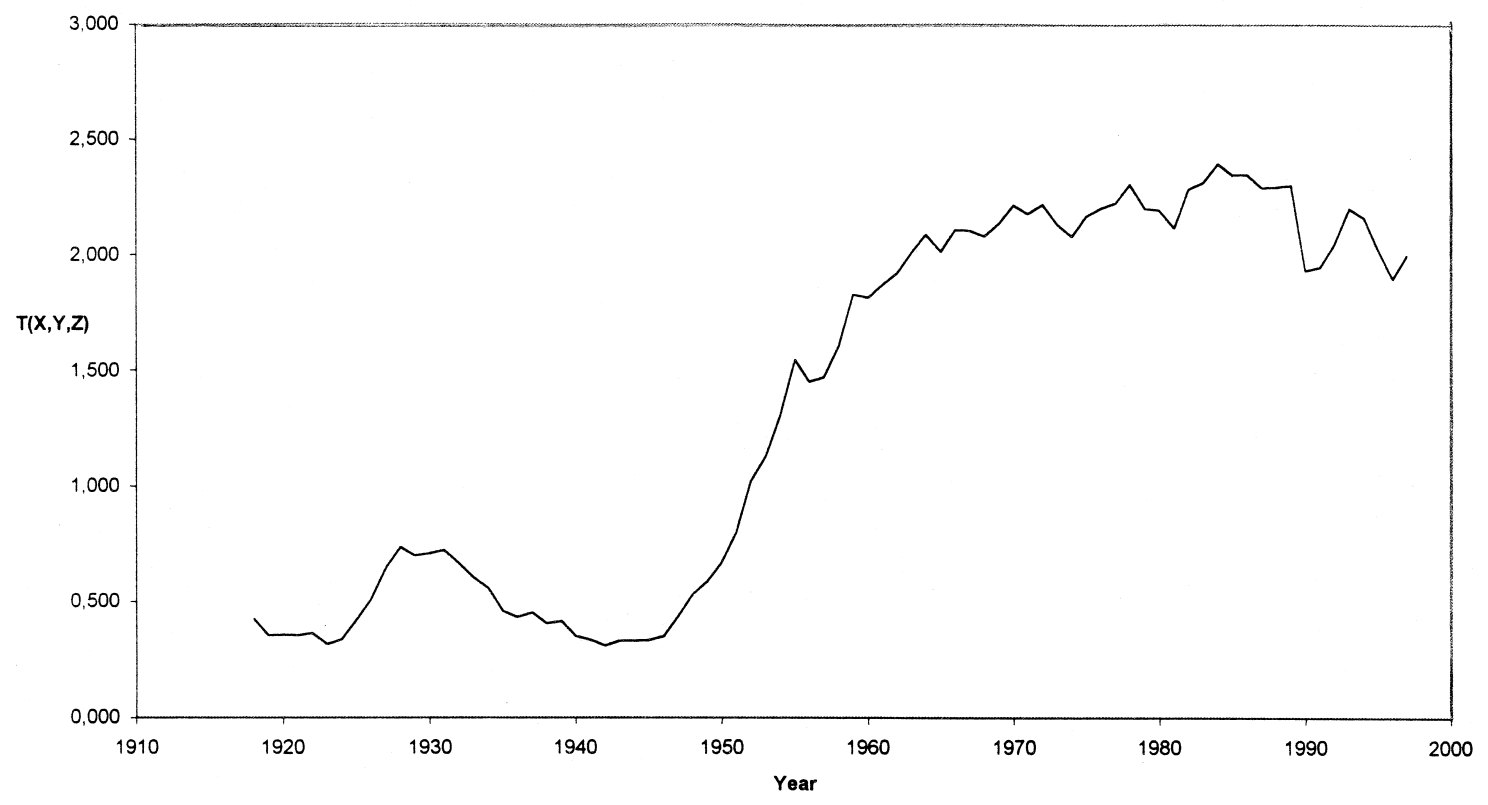

Scheme 1. Mutual information values $T(X, Y, Z)$ among technologies, markets and countries.

The highest specialization values for individual networks are found, as expected, in the postwar period. One very strong coupling is found for the network of piston propeller producers, business aircraft users in the USA with $p_{i j k} \log _{2}\left(p_{i j k} /\right.$ $\left.p_{i .} p_{. j .} p_{. k}\right)$-values up to 0.44 bits. ${ }^{10}$ The high concentration of customers for business aircraft in the American home market points to the importance of users in this innovation network. In the military domain strong specialization is found for the USA, the former USSR, France, Italy and Sweden in jet fighters with values between 0.10 bits and 0.20 bits, with France and the USSR switching from jet to turbofan fighters after 1970. Only the USSR shows a clear specialization pattern in bombers using turboprop technology with specialization values close to 0.10 bits. In the civil market, we find pronounced specialization patterns in turboprop passenger aircraft for the UK (up to 0.17 bits), Czechoslovakia

\footnotetext{
${ }^{10}$ Note that mutual information is based on relative frequencies and not in absolute frequencies (the United States dominated in many more technology-market segments in absolute terms).
}

(up to 0.12 bits), China (up to 0.11 bits), and Brazil (up to 0.6 bits). The USA specialized in turbofan passenger aircraft with highest values around 0.10 bits. Canada dominated the market niche for STOLaircraft using turboprop technology with values close to 0.09 bits and Argentina specialized in turboprop cargo aircraft with values close to 0.10 bits.

The focus on a particular technology/market segment in relatively "small" aviation countries like Argentina, Brazil, Canada, China, and Czechoslovakia can be considered as a strategy to limit competition with larger countries profiting from economies of scale and political dominance (in particular, the USA and the USSR). The concentration of efforts in smaller countries to a particular technology and application contributed to the sustainability of their aircraft industry. The need for these countries to specialize is an empirical outcome, and may be specific to aircraft technology. In other types of industries, there are examples of small countries that have been very successful in mass markets, as Sweden has been in mobile phones and furniture.

It should be noted that the specialization patterns among countries do not necessarily follow the logic 
Mutual information technologies/markets

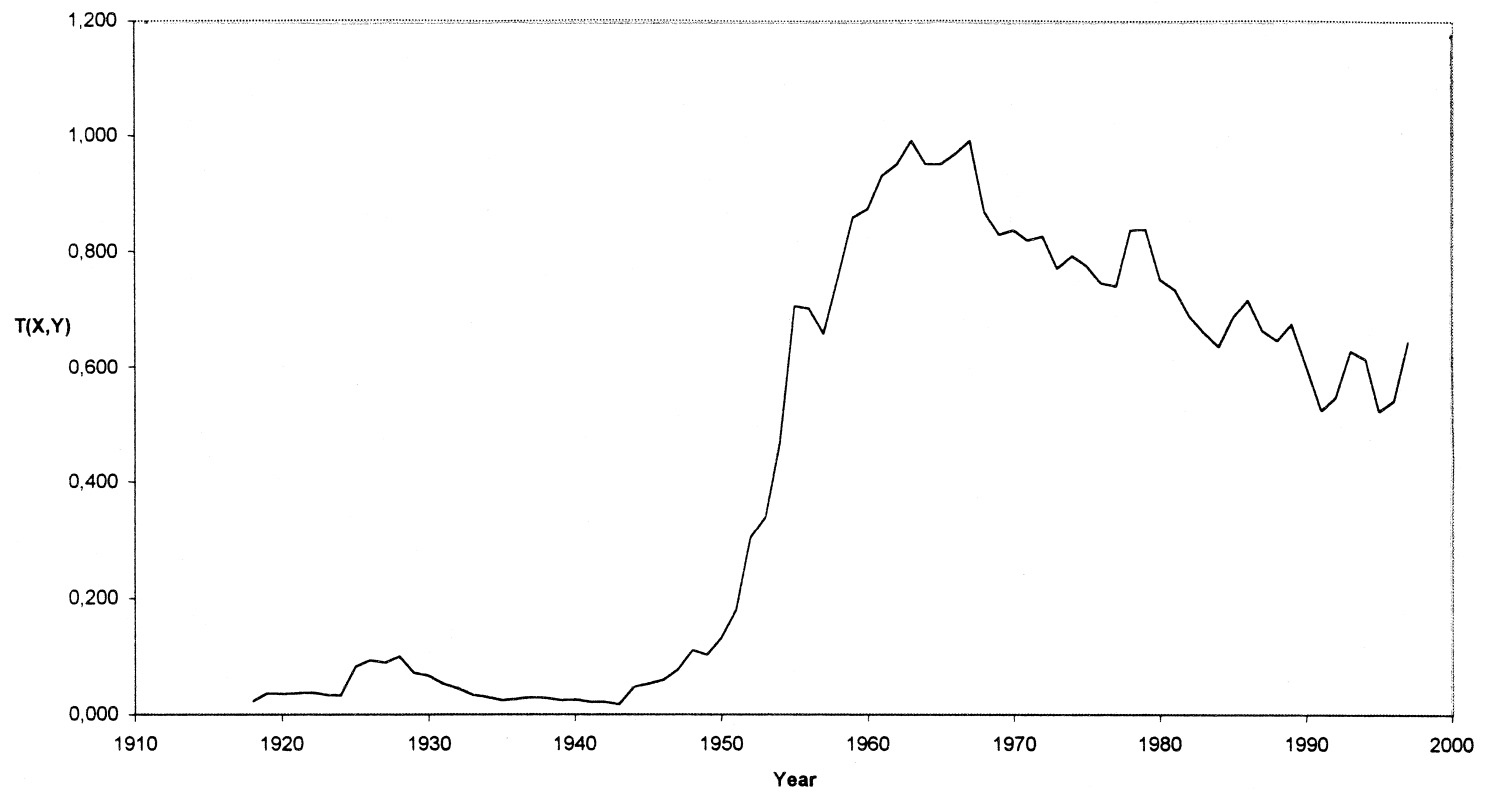

Scheme 2. Mutual information values $T(X, Y)$ among technologies and markets.

\section{Mutual information technologies/countries}

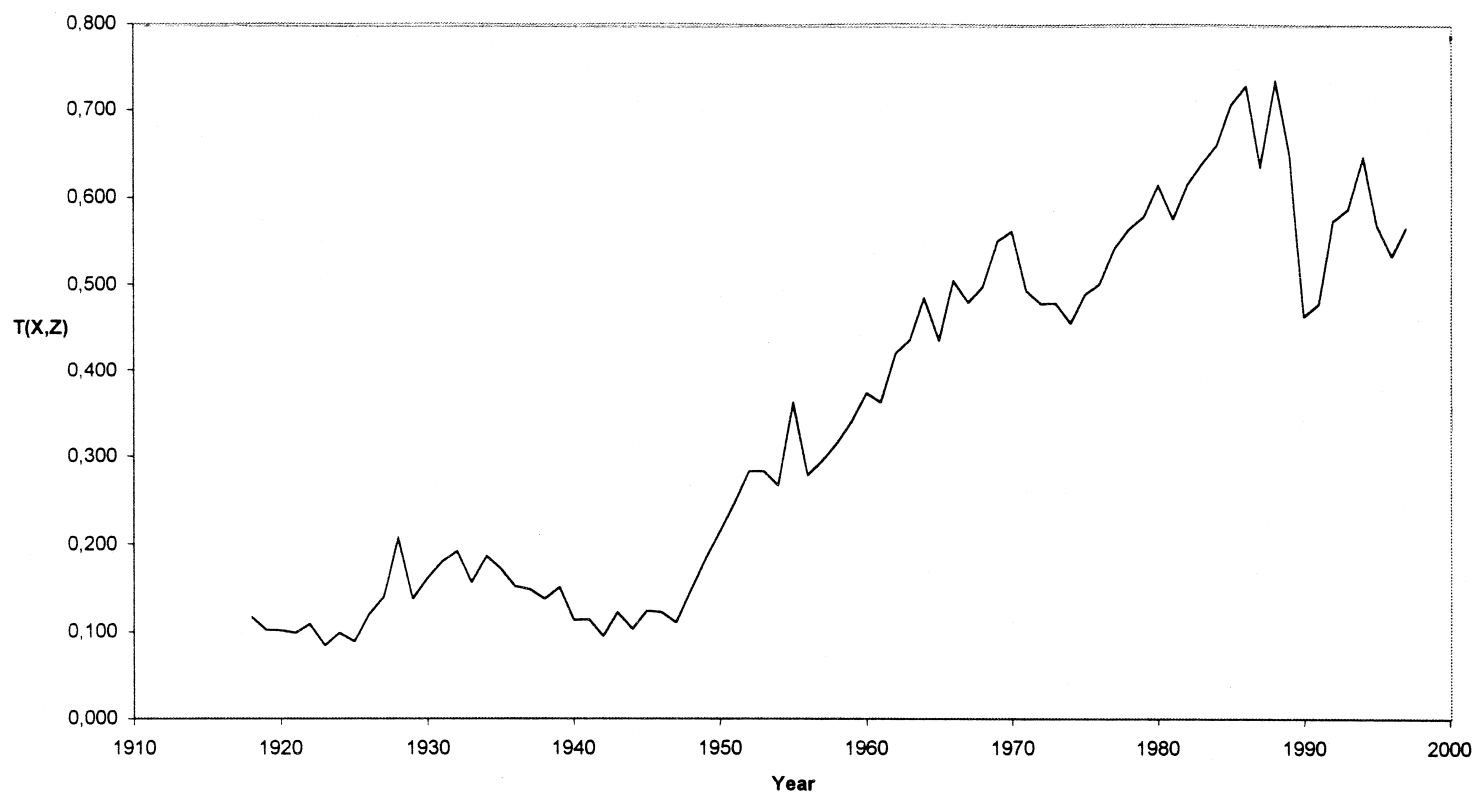

Scheme 3. Mutual information values $T(X, Z)$ among technologies and countries. 
of the product life-cycle as put forward by Vernon (1966). In short, this thesis holds that as a technology becomes standardized, the technology is easily transferred from more developed, high-wage to less developed, low-wage countries. This dynamic is clear in the case of turbopropeller technology, which moved from the UK to newly industrializing countries such as Argentina, Brazil and China. However, in the case of the even older piston propeller technology, the USA remained the dominant country throughout its life-cycle. The simple fact that at the end of its life-cycle, piston propeller technology has been predominantly applied in business aircraft segment explains why the American firms are still dominant in the development of this technology: localized user-producer interaction may prevent the standardized technology from moving to low-wage countries.

\subsection{Two-dimensional specialization patterns}

As explained in Section 4, the $T(X, Y, Z)$-measure is a summary measure which can be further analyzed in terms of the two-dimensional, "bilateral", specialization patterns among each of the three pairs of dimensions. The $T(X, Y)$-values for the coupling between technologies and markets are provided in
Scheme 2, the $T(X, Z)$-values for the coupling between technologies and countries in Scheme 3, and the $T(Y, Z)$-values for the coupling between markets and countries in Scheme 4. As for the results of $T(X, Y, Z)$, we find in all three schemes low values before 1945 and sharply rising values during the 1950s and 1960s. One striking difference between the schemes arises around the mid-1960s, when the coupling between technologies and markets $T(X, Y)$ decreases again, while the values for technologies and countries $T(X, Z)$, and for markets and countries $T(Y, Z)$, keep on rising till the early 1990 s. Thus, the elaborated analysis of three-dimensional specialization patterns in terms of two-dimensional specialization patterns proves informative.

As noted, there has been a strong coupling between technology and markets after the Second World War as new technologies were introduced in particular market segments. Turboprops initially dominated in markets for cargo aircraft and bombers, jets in the fighter market, and turbofans in the passenger market. The older piston propeller technology remained the standard in business and trainer aircraft. These patterns changed after the mid-1960s, when engine technologies in bombers and fighter aircraft were gradually substituted by turbofan engines, resulting in a fall in $T(X, Y)$. During the 1980s and 1990s,

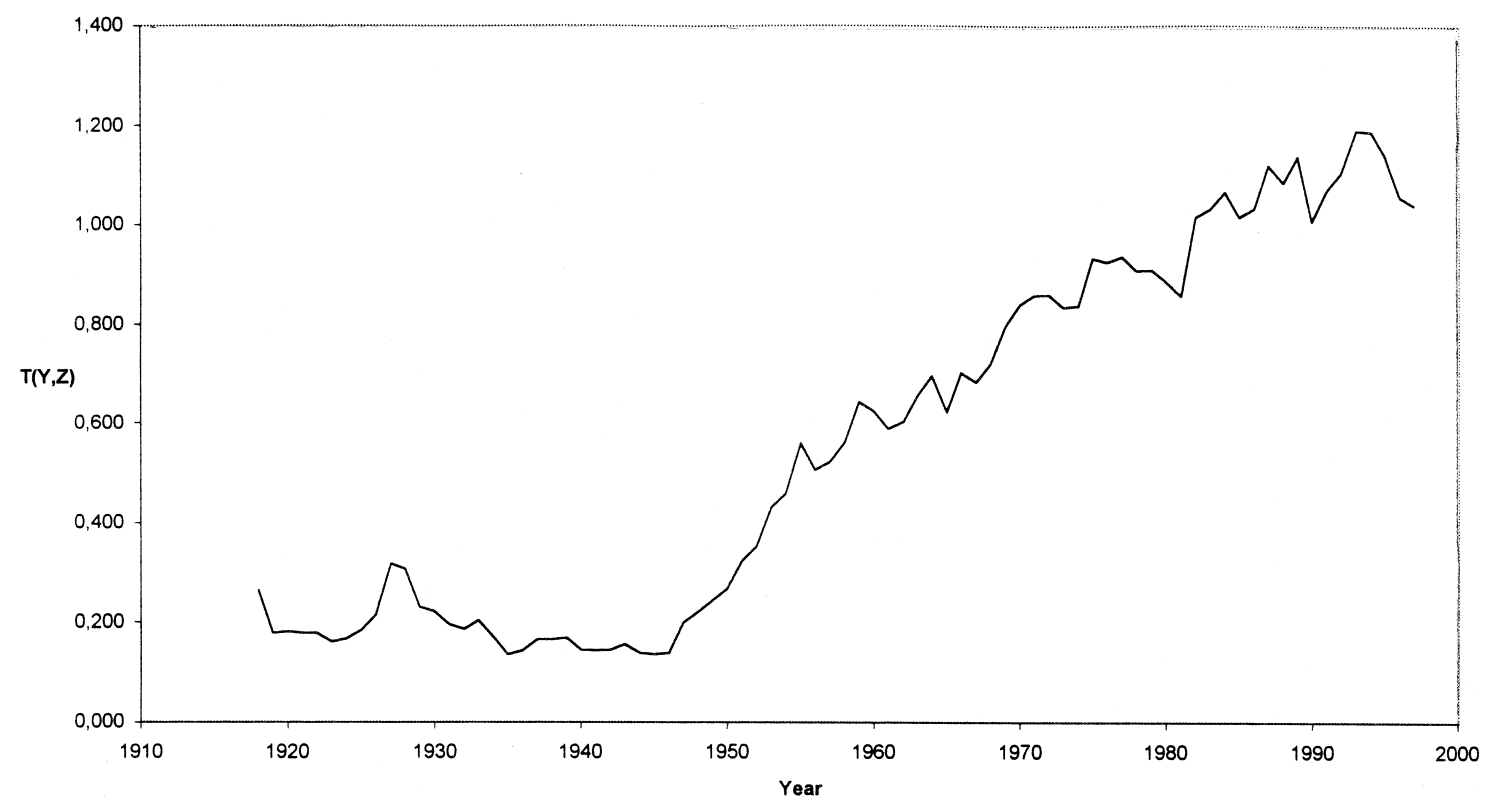

Scheme 4. Mutual information values $T(Y, Z)$ among markets and countries. 
turbofan technology further extended its range of applications towards business aircraft, leaving only the trainer, cargo, and STOL-markets to be dominated by piston propellers and turboprops. These results show that turbofan technology has established itself as the second technological paradigm across all major markets. The cyclical pattern in Scheme 2 can be understood as evidence of two technological paradigms in the aircraft history (Constant, 1980), but it is clear that the recent second paradigm of turbofan monoplanes has not been as dominant as the first paradigm of piston propeller monoplanes. Though turbofan technology has expanded its range of application, some alternative technologies survive in niches (Frenken et al., 1999b).

The important conclusion to be drawn from these results is that the establishment of turbofan technology as a technological paradigm across various markets did not lead to a de-specialization of countries in technologies. The values of $T(X, Z)$ in Scheme 3 keep on rising after the 1960s, indicating that technologies other than the paradigmatic turbofan technology continued to develop in specific countries. In particular, as noted above, a number of small countries successfully pursued a turbopropeller trajectory in specific niche segments (Brazil in passenger aircraft, Canada in STOL-aircraft, and Argentina in cargo-aircraft). Furthermore, countries like China and India that entered the segment of fighter aircraft applied predominantly jet engine technology. Thus, the spread of the paradigmatic turbofan technology at the global level did not impede specific countries from specializing in an alternative technology: different countries explore their own opportunities that result from complementarities with specific technologies and markets.

In sum, before 1945, the degree of specialization was low; it reached its lowest values in the 1930 s and early 1940s when the piston-propeller-monoplane paradigm was established. After 1945, innovation in the aircraft industry became increasingly localized in specific innovation networks, as predicted by the $N K$-model. While the trend toward national specialization patterns in technologies and markets kept rising during the whole post-war period, the degree of coupling between technologies and markets fell after 1965. At this time, turbofan technology diffused across all major markets and established itself as the new technological paradigm. However, several countries successfully maintained their aircraft industry by focusing on alternative technologies in specific market segments. More generally, our complexity approach to innovation networks implies that local dynamics cannot be derived from the global dynamics, though the latter is constituted by the aggregate of the former.

\section{Transnational networks: an emerging regime?}

Among other high-tech industries, aviation has witnessed a rapid increase in transnational networks among firms that have co-developed high-risk innovations. The development of the Concorde by Aerospatiale and BAe was one of the first collaborations within a European context. More prominently, Airbus has been successful in developing passenger aircraft using turbofan technology. This has set the stage for new European networks, such as Avions de Transport Regional (ATR), and more recently Aero International Regional (AIR). In military aircraft, European collaborations date back to Panavia, established in 1969, and have been extended with Eurofighter and Europatrol. Similarly, European Helicopter Industry (EHI) and Eurocopter have become major players in the European helicopter industry.

How can we understand the recent rise of transnational networks against the background of the $\mathrm{NK}$ model of innovation networks as discussed above? In the model, a technology-market-country triple counts as one innovation network between a producer type, user type, and a national government. A transnational innovation network then is a particular type of innovation network classified according to one technology, one market and two or more countries. For example, Airbus is classified as a network developing turbofan technology for the passenger market with a French-German-British-Spanish "'government'. The question becomes which countries are expected to collaborate with one another. From an evolutionary perspective, one expects that countries in a transnational collaboration recombine their individual national specialization pattern. Insofar as two countries are specialized in different technology-market combinations, they can collaborate in two ways: one country can recombine the technology in which it is specialized, with the market in which 
the other country is specialized, and vice versa. The recombination of specialization patterns allows partners to explore a new technology-market trajectory collectively. Below, we discuss two European examples in further detail: the Concorde project and the Airbus consortium.

The Concorde aircraft was co-developed by Aerospatiale (France) and BAe (UK). This collaboration is indeed an example of a combination of two existing national trajectories. The Concorde is a jet engine passenger aircraft developed during the 1960s and introduced in 1969. At the time, France was specialized in jet technology (for fighter purposes) and the UK had a long record in the passenger market (mostly using turboprops). The Concorde is the first passenger aircraft with a delta wing construction, which had also been used in several French fighters developed in the 1950s.

The second example concerns the European Airbus consortium, which started developing aircraft in the late 1970s. The consortium is again a collaboration between Aerospatiale and BAe together with the German firm DASA and the Spanish firm CASA. Airbus concentrated its product innovations exclusively on passenger aircraft using turbofan technology. At the time of the establishment of Airbus, France had just switched its technological base from jets to turbofans, while the UK was still specialized in passenger aircraft. Again, previous specialization patterns are reflected in the technoeconomic specialization of the transnational network. However, the other two countries Germany and Spain had little experience in aircraft technology, and had previously specialized in other domains. For these countries, Airbus provided an opportunity to leave their old specialization pattern and to enter a new market segment using state-of-the-art technology. The entry of Airbus in the turbofan passenger market can be understood as a recombination of competencies for some countries, and a developing strategy for other countries.

An interesting aspect in the history of Airbus concerns the Dutch firm Fokker, which was invited to participate in the Airbus-consortium at an early stage (Hayward, 1986). At that time, Fokker exclusively built aircraft for short-range passenger flights, and like Airbus it was aiming to move into the segment of long-range turbofan passenger aircraft.
However, Fokker preferred an independent position in Europe, and started a collaboration with the American firm McDonnell Douglas in the early 1980s to develope a turbofan passenger aircraft. The collaboration failed after six months of collective design and marketing studies (Green and Swanborough, 1982). Fokker then individually introduced the turbofan F.100 in 1986 followed by the turbofan F.70 in 1993. At the same time, the turbopropeller product line was extended with the F.50 in 1985 and the F.60 in 1995. During the 1990s, Fokker ran into capacity and payment problems, which led the national government to withdraw its subsidies from its sole aircraft industry. From the perspective of the model, the lack of a technological specialization pattern in the Dutch aircraft industry may have contributed to its recent breakdown. With hindsight, integration into a European framework could have provided a more appropriate scale on which to face global competition.

The examples of the Concorde and Airbus do not warrant any strong conclusion regarding the specificity of transnational network formation. Rather, they are meant as illustrations of institutional innovations that allow countries to explore new product trajectories collectively. The recombination of national specialization patterns at the transnational introduces a nested governance structure. Transnational networks can experiment with new combinations between technologies and markets without destroying existing specialization patterns at the national level. Stable specialization patterns at the level of countries, however, are not sufficient for transnational recombination, but historically contingent on political considerations. Once a transnational collaboration is in place, its continuation is largely dependent on its commercial success. When experiments prove to be failures, other recombinations are still possible since the national patterns are still in place. Thus, vested interests in national innovation networks are compatible with the exploration of new trajectories at a supra-national level. In the European context this implies that the formulation of common technology policies does not preclude the continuation of programs at the national level.

As explained above, the example of Airbus is important in more than one respect. On the one hand, the consortium built upon the national competencies 
of France and the UK. On the other hand, it served as a strategy to develop an aircraft industry in Germany and Spain. Technology transfer through transnational collaboration has not been confined only to Europe. Non-European examples include the Italian-Brazilian collaboration within AMX which allowed Brazil to enter the turbofan fighters market in the late 1970s, and the Spanish-Indonesian collaboration within Airtech established in 1980 which launched Indonesia into cargo and passenger transport using turboprop technology. More recently, Airbus and Alenia have started negotiations with China's AVIC and Singapore's STPL in an attempt to secure a strategic position in commercial aircraft in the Far East (Jane's, 1998).

The transnational network model of technology transfer has important implications for government policies aiming at penetrating a high-tech industry. Compared to earlier technology transfer practices, the network model constitutes an institutional innovation. Just after the Second World War, many countries followed a transfer model via licensing agreements to (re-) vitalize their aircraft industries. In retrospect, this model can be considered a typical Cold-War institution as the United States and the former USSR licensed most aircraft designs. Importantly, licensing involves what can be called "firstorder" knowledge transfer, as the knowledge transferred concerns the production technology of an existing aircraft. In contrast, the network model is based on the co-development of new aircraft, which allows participating parties to exchange (tacit) knowledge and to extend their individual competence bases collectively. This form of collaboration can be called "second-order" knowledge transfer since the knowledge transferred concerns the development of new aircraft designs. Thus, the collaboration aims at a collective output, and is in essence a process-oriented transfer model. It allows countries to catch up with state-of-the-art design procedures that can be put to further use in future product developments.

\section{Summary}

The $N K$-model provides us with a heuristic simulation of complex innovation networks of producers, users, and national governments. We derived from the model that among the possible combinations, there are many local optima to be expected. Networks will then specialize among these local optima, which reflect the complementary combinations among technologies, markets, and countries. Empirical analysis of product innovations in the aircraft industry shows that the degree of specialization increased rapidly after the Second World War. This result suggests that the "complexification" of innovation networks in the aircraft industry is a historical phenomenon emerging after the Second World War.

The complexity of innovation networks renders the outcomes of the strategic choices of national governments highly uncertain. The scope for clear-cut policies is limited since the viability of specialization patterns cannot be judged ex ante, but only be discovered ex post. Nevertheless, some preliminary conclusions have been drawn that merit further research. First, the pattern of specialization that emerged in the post-war aircraft industry shows that a number of small countries started to focus on particular technology/market combinations. By means of focusing research and development in a very specific area, these countries have been able to sustain a viable position vis-à-vis larger countries profiting from economies of scale and political dominance. Second, we concluded that transnational networks might become the new model of technology transfer, since these networks allow countries to recombine their competencies by co-developing product innovations.

\section{Acknowledgements}

Financial support from the European Commission TMR-grant ERB4001GT961736 is gratefully acknowledged. The research reported here is partly based on data gathered in a previous project funded by the ESRC (Saviotti, 1996). I thank Henry Etzkowitz, John Grin, Cooper Langford, Stéphane Lemarié, Loet Leydesdorff, Shyama Ramani, Paolo Saviotti and Michel Trommetter for their comments on previous versions of the paper. 


\section{References}

Alchian, A., 1950. Uncertainty, evolution, and economic theory. Journal of Political Economy 58, 211-221.

Arthur, W.B., 1989. Competing technologies, increasing returns, and lock-in by historical events. Economic Journal 99, 116131.

Axelrod, R., 1997. The Complexity of Cooperation. Agent-Based Models of Competition and Collaboration. Princeton Univ. Press, Princeton.

Constant II, E.W., 1980. The Origins of the Turbojet Revolution. Johns Hopkins Univ. Press, Baltimore, MD.

Dalle, J.-M., 1997. Heterogeneity vs. externalities in technological competition: a tale of possible technological landscapes. Journal of Evolutionary Economics 7, 395-413.

Dosi, G., 1982. Technological paradigms and technological trajectories. A suggested interpretation of the determinants and directions of technical change. Research Policy 11, 147-162.

Freeman, C. Perez, C., 1988. Structural crisis of adjustment, business cycles and investment behaviour. In: Dosi, G., Freeman, C., Nelson, R., Silverberg, G., Soete L. (Eds.), Technical Change and Economic Theory. Pinter, London, pp. 38-66.

Frenken, K., Marengo, L., Valente, M., 1999. Interdependencies, nearly-decomposability and adaptation. In: Brenner, T. (Ed.), Computational Techniques to Model Learning in Economics. Kluwer, Boston, 145-165.

Frenken, K., Saviotti, P.P., Trommetter, M., 1999b. Variety and niche creation in aircraft, helicopters, motorcycles and microcomputers. Research Policy 28, 469-488.

Green, W., Swanborough, G. 1982. The World's Civil Airliners, Salamander Books, London.

Hayward, K., 1983. Government and British Civil Aerospace. A Case Study in Post-War Technology Policy. Manchester Univ. Press, Manchester.

Hayward, K., 1986. International Collaboration in Civil Aerospace, Pinter, London.

Jane's, 1978. Jane's Encyclopedia of Aviation, Jane's Publishing, London.

Jane's, 1989. Jane's Encyclopedia of Aviation (Studio Editions; London).

Jane's, 1998. Jane's All the World's Aircraft 1997-98, Jane's Information Group, Surrey.

Kauffman, S.A., 1993. The Origins of Order. Self-Organization and Selection in Evolution. Oxford Univ. Press, Oxford.

Kemp, R., 1994. Technology and the transition to environmental sustainability. Futures 26, 1023-1046.

Levinthal, D., 1997. Adaptation on rugged landscapes. Management Science 43, 934-950.

Leydesdorff, L., 1995. The Challenge of Scientometrics. The Development, Measurement, and Self-Organization of Scientific Communications. DSWO Press, Leiden Univ., Leiden.

Leydesdorff, L., 1998. The triple helix as an evolutionary model. Paper presented at the Second Symposium on the Triple Helix of University-Industry-Government Relations "The Future Location of Research", New York, 7-10 January.

Leydesdorff, L., Etzkowitz, H., 1996. Emergence of a triple helix of university-industry-government relations. Science and Public Policy 23, 279-286.

Lundvall, B., 1988. Innovation as an interactive process: from user-producer interaction to the national system of innovation. In: Dosi, G., Freeman, C., Nelson, R., Silverberg, G., Soete, L. (Eds.), Technical Change and Economic Theory. Pinter, London, pp. 349-369.

Miller, R., Sawers, D., 1968. The Technical Development of Modern Aviation. Routledge and Kegan Paul, London.

Mowery, D.C., Rosenberg, N., 1982. The commercial aircraft industry. In: Nelson, R.R. (Ed.), Government and Technical Progress. A Cross-Industry Analysis. Pergamon, New York, pp. 101-161.

Nelson, R.R., 1994. Economic growth via the co-evolution of technology and institutions. In: Leydesdorff, L., Van den Besselaar, P. (Eds.), Evolutionary Economics and Chaos Theory: New Directions in Technology Studies. Pinter, London, pp. 21-32.

Nelson, R.R., Winter, S.G., 1977. In search of useful theory of innovation. Research Policy 6, 36-76.

Rip, A., Misa, T., Schot, J., 1995. Managing Technology in Society. The Approach of Constructive Technology Assessment, Pinter, London.

Rosenberg, N., 1982. Inside the Black Box. Cambridge Univ. Press, Cambridge.

Saviotti, P.P., 1996. Technological Evolution, Variety and the Economy. Edward Elgar, Cheltenham and Brookfield.

Scharnhorst, A., 1998. Citation - networks, science landscapes and evolutionary strategies. Scientometrics 43, 95-106.

Soete, L.G., Wyatt, S.M.E., 1983. The use of foreign patenting as an internationally comparable science and technology output indicator. Scientometrics 5, 31-54.

Theil, H., 1967. Economics and Information Theory. North-Holland, Amsterdam.

Theil, H., 1972. Statistical Decomposition Analysis. North-Holland, Amsterdam.

Van den Belt, H., Rip, A., 1987. The Nelson-Winter-Dosi model and synthetic dye chemistry. In: Bijker, W., Hughes, T.P., Pinch, T. (Eds.), The Social Construction of Technological Systems. MIT Press, Cambridge, MA, pp. 135-158.

Vernon, R., 1966. International investment and international trade in the product life-cycle. Quarterly Journal of Economics 80, 190-207.

Von Hippel, E., 1988. The Sources of Innovation. Oxford Univ. Press, Oxford.

Windrum, P., Birchenhall, C., 1998. Is product life-cycle theory a special case? Dominant designs and the emergence of market niches through coevolutionary learning. Structural Change and Economic Dynamics 9, 109-134. 